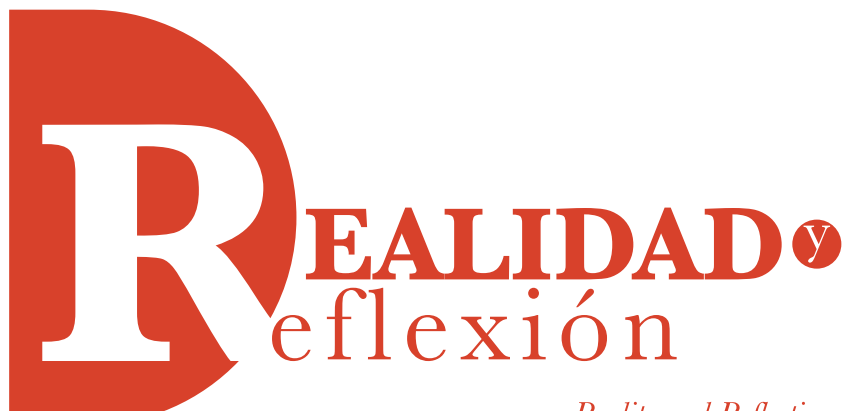

ISSN 1992-6510

e-ISSN 2520-92990

Reality and Reflection

Año 17, N 45, San Salvador, El Salvador, Centroamérica. Revista Semestral Enero-Junio 2017

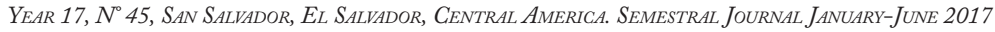

\title{
Discurso de aceptación del Doctorado Honoris Causa en Educación de la Universidad Francisco Gavidia
}

\section{Acceptance speech for the Honoris Causa PhD in Education by Francisco Gavidia University}

(San Salvador, 7 de marzo de 2017)

Ing. René Toruño

Ing. Mario Ruiz, rector de la Universidad Francisco Gavidia

Dr. Óscar Picardo Joao, director Instituto de Ciencia, Tecnología e Innovación

Lcda. Teresa de Jesús González de Mendoza, Secretaria General

Lcda. Rosario Melgar de Varela, presidenta del Consejo Directivo

Miembros del Consejo Directivo

Decanos

Directores

Invitados especiales

Mi querida esposa Jutta

Amigos de la prensa

Amigos todos: 
Un día como hoy para un ser humano, y yo no soy la excepción, es inimaginable, pues estar en este estrado y recibir esta distinción maravillosa, es una bendición de Dios.

Lo describo de esta manera, pues yo no me preparé para recibir esto, fue obra de Dios que me dio unos valores y herramientas a través de la educación, y hoy, este prestigioso centro de estudios que promueve educación, la Universidad Francisco Gavidia, considera que esos valores educativos que me inculcaron han sido solidarios para con la sociedad en la que vivo y en la que me he desarrollado.

Reciban mi gratitud amigos de la Universidad Francisco Gavidia, la de mi familia, la de mis colaboradores, la de quienes contribuyeron a mi educación, pues son ellos los que han construido y siguen construyendo mis valores $y$ mi solidaridad.

¡Doctorado Honoris Causa! Una distinción por razón o causa de honor sin tener que pasar por los trámites necesarios para obtenerlos, sino como reconocimiento a méritos especiales. Así reza la filosofía y el concepto de un honoris causa y es por el que la Universidad Francisco Gavidia, en este caso, lo ha considerado y me lo otorga. Gran honor que me han hecho con esta consideración. Gracias en nombre mío y de mi familia.

Es un honor también recibir este reconocimiento en una fecha muy especial para este centro de estudios universitarios, ya que está cumpliendo 36 años de fundación, y me emociona aún más, saber que es el cuarto honoris causa que otorgan en estos 36 años. Reciban también nuestra felicitación por esa invaluable labor para con la sociedad salvadoreña y especialmente, con la juventud, en este valioso tiempo.

Un reconocimiento que me emociona, y a su vez, alimenta mi obstinada preocupación por la educación. Porque me actualiza que valió la pena el esfuerzo y sacrificio en mi juventud, por poner el estudio sobre las atracciones que son propias de la juventud. Porque con ese sacrificio logré esa beca de estudios universitarios de Ingeniería que realicé en Alemania, y que me permitieron la formación del hombre útil, social y empresario que soy hoy.

No perfecto, pero sí con los valores y educación a los que les doy mantenimiento con acciones que son insumos para hacer más que para ser.

¿Qué decir en un momento de estos, además del agradecimiento? Una pregunta que me hice cuando armonizaba estas palabras.

Quienes pensaron en este servidor para este doctorado son los que encontraron méritos en mis acciones de servicio y ya ustedes escucharon las causas, así que me ahorraron hablar de mí que nunca me ha gustado, soy un hombre de acciones no de palabras.

De tal manera que decidí compartir mejor las reflexiones que ocurrieron en la mente cuando me lo informaron y que se derivan de ese momento.

Reflexiones que hago basadas en mi experiencia personal y con ellas, pretendo hacer solo un resumen crítico y autocrítico, quizás poco usual creo, intentando ofrecer la experiencia que la educación ha hecho en mi vida y la importancia 
que considero esta tiene para nuestro país, y para que nuestra sociedad pueda enfrentar, de mejor forma, la crisis de desarrollo en que vivimos. $\mathrm{Y}$ reflexionaré $\mathrm{mi}$ agradecimiento sobre la educación, para ser congruente con esta institución educativa que hoy me honra con este doctorado.

La educación es innegable que juega hoy el papel más importante y fundamental para hacerle frente a la ola de inseguridad, violencia, incertidumbre y pobreza en que se vive. Miro hacia arriba con la esperanza de que la educación acuda a ese llamado, pues es una realidad que nuestra sociedad padece de estas enfermedades por falta de educación.

Pero es importante a su vez entender que necesitamos una educación que no solo se limite a exponer el bagaje que sustenta una cultura. No. Necesitamos una educación desde el hogar hacia la escuela y la universidad. Una educación donde los jóvenes sean ciudadanos del mundo, que respeten a sus semejantes, que practiquen la tolerancia, que vivan los derechos humanos; que sus conductas se rijan por el respeto $y$ la honestidad. Ahora ya no solo debemos educarnos para saber, para ser, para tener. Ahora debemos educarnos con solidaridad para hacer, para convivir.

La educación también se transforma y evoluciona. Yo me eduqué bajo otras formas, parámetros e instrumentos. Hoy tenemos muchos instrumentos nuevos: medios digitales, internet, redes sociales, etc. y sin embargo, $y$ con las disculpas del caso, las enfermedades de pobreza, hambre y delincuencia son más dramáticas ahora y nos están destruyendo.
¿Cuál es la medicina? Señoras y señores, amigos todos, es solo una la medicina: la educación. La educación es la medicina natural para mantener una sociedad saludable.

Ahora la queremos desarrollar con acciones inmediatistas y otras con fines políticos, pero las primeras solo alivian el dolor del momento y las otras, atraen votos solo para el momento.

Tampoco dejemos que nos siga asaltando el otro delincuente, el de la desesperanza. Este delincuente que ataca a educados y no educados haciéndonos creer que no saldremos de este momento.

Venzamos a este delincuente con la educación que da valores. Trabajemos para construir y formar una sociedad digna. Dios sabio y creador, creó un mundo para vivir en convivencia, no solo para llevar agua al molino de cada quien. Puso frutos para todos no para unos pocos. Dejó establecido que amáramos al prójimo como a nosotros mismos.

¿Es imposible atacar la desesperanza? No. La meta de la educación es la sabiduría y la sabiduría es la herramienta para hacer el bien.

Pero la educación no es exclusiva del hogar, de la escuela, de los padres, de la universidad, de los maestros. La educación es de todos.

Da pena pero es una realidad, creamos instituciones para la defensa y supervisión de los derechos humanos. Y los derechos humanos ¿no es acaso una práctica de humanos que traemos desde que nacemos? Sí, desde que nacemos: pido respeto, pero también doy respeto. Pido defensa 
de mis derechos, pero también debo respetar los derechos de los otros.

El derecho a la calidad de vida es un derecho que no solo debe estar escrito en la constitución, debe estar implícito en nuestros valores, en nuestro ser.

Hoy da tristeza leer que en nuestro país se cierran escuelas, que la deserción escolar aumenta. Y por otro lado, se están construyendo nuevas cárceles. ¿Por qué? ¿Qué estamos educando? Definitivamente algo anda mal en nuestro país.

Pero también soy un convencido de que la educación es de todos. Todos debemos involucrarnos.

Hay un proverbio chino que reza: "Dímelo y lo olvidaré. Muéstramelo y puede que no lo recuerde. Involúcrame y lo entenderé”.

Comparto este proverbio porque tengo la intención de que aprendamos a involucrarnos en pro de la educación.

Hablaré de mi experiencia y discúlpenme que lo haga con una de mis acciones pues puede parecer que busco echarme flores, pero no.

INDUFOAM empresa que presido y soy propietario, invertimos en la educación de $\mathrm{E} 1$ Salvador, a través de FEPADE (Fundación Empresarial para el Desarrollo), institución sin fines de lucro, otorgando 2,600 becas desde 1999, por medio de su programa Edubecas, destinando para ello 100. 000, 00 dólares anuales.

También a través de un convenio que FEPADE tiene con AID (Agencia de Estados Unidos para el Desarrollo) y el programa "Empresarios por la Educación" hemos construido el Complejo Educativo “René Toruño Steiner”, en San Andrés, con dos institutos donde se obtienen bachilleratos en Ingeniería Industrial y otro en Confección.

Hemos mejorado las instalaciones de la Escuela San Francisco en Ciudad Arce y hemos construido el Complejo Educativo "Jutta Steiner de Toruño”, en el cantón Santa Lucía, donde se graduarán bachilleres en "Procesamiento de Datos".

En este programa, por cada dólar que aportamos con la Fundación “Toruño Steiner”, AID aporta lo mismo. Nosotros construimos los edificios y AID aporta el equipamiento y la capacitación del profesorado.

Son estos, institutos únicos y primeros en su género educativo, que tienen que ver con la tendencia actual educativa.

Invirtamos en educación. Contribuyamos a la educación desde cualquier trinchera, pero por favor no compremos prebendas a través de la educación. No lucremos con la educación. Construyamos valores por medio de la educación.

Y cuando hablo de valores, estos también tienen el derecho de disentir con respeto. Se me viene a la mente un principio de respeto que alguien escribió: "Quizás no esté de acuerdo con lo que piensas, pero daría mi vida por saber lo que piensas".

La convivencia y el respeto por las ideas del otro son virtudes que enseña la educación. Un pueblo sin educación es víctima de delincuentes del poder, del autoritarismo, de las dictaduras. 
Tampoco torzamos el intelecto que nos da la educación. No aprovechemos la educación para esclavizar a los no educados, porque también hay educados que enseñan injusticias, corrupción y deshonestidad.

$\mathrm{Y}$ termino reflexionando con las palabras del filósofo Alemán de 1770, Emmanuel Kant, que desde esa época pensaba en cómo educar para una educación en evolución: "Hay que educar a los niños no solo pensando en el presente, sino para una condición futura, posiblemente mejorada, de manera que se adapte a la idea de la humanidad y al destino del hombre".

Los que tienen el privilegio de haberse educado y los que están educándose, tomemos con responsabilidad de hacerlo con la convicción de ser para hacer.

Y los que tengamos la posibilidad de invertir en la educación hagámoslo, seguro que será el mejor logro de su vida, de su estabilidad y del futuro de sus hijos y nietos.
Invertir en educación desde cualquier centro de estudios, rincón, pueblo, hogar, empresa y Gobierno, será para nosotros los salvadoreños la mejor inversión para salir de esa obscuridad en la que permanecemos y abrigar la esperanza de alcanzar esa aurora que nos lleve al anunciado amanecer donde vivamos con justicia social, con responsabilidad social, con igualdad de condiciones, sin ignorancia, sin delincuencia y sin pobreza. Algo que es única y exclusivamente posible, a través de la educación.

Reitero mi agradecimiento por este honor y por este Doctorado Honoris Causa y sepan que lo ejerceré con las responsabilidades y exigencias que trae consigo.

Mi saludo a este prestigioso centro de estudios, a sus autoridades, profesorado y alumnos. Sepan que este doctorado que hoy se me otorga me hace parte de ustedes, así que mi corazón es ya UFG.

Muchísimas gracias y que Dios los bendiga a todos. 